Abstracta Iranica Abstracta Iranica

Revue bibliographique pour le domaine irano-aryen

Volume 28 | 2007

Comptes rendus des publications de 2005

\title{
Abbas Kiarostami. Urbana and Chicago, University of Illinois Press, 2003, 151 p.
}

\section{Agnès Devictor}

\section{(2) OpenEdition}

1 Journals

\section{Édition électronique}

URL : http://journals.openedition.org/abstractairanica/7482

DOI : 10.4000/abstractairanica.7482

ISSN : 1961-960X

Éditeur :

CNRS (UMR 7528 Mondes iraniens et indiens), Éditions de l'IFRI

Édition imprimée

Date de publication : 15 mai 2007

ISSN : 0240-8910

\section{Référence électronique}

Agnès Devictor, « Abbas Kiarostami. Urbana and Chicago, University of Illinois Press, 2003, 151 p. », Abstracta Iranica [En ligne], Volume 28 | 2007, document 534, mis en ligne le 18 septembre 2007, consulté le 25 septembre 2020. URL : http://journals.openedition.org/abstractairanica/7482 ; DOI https://doi.org/10.4000/abstractairanica.7482

Ce document a été généré automatiquement le 25 septembre 2020.

Tous droits réservés 


\title{
Abbas Kiarostami. Urbana and Chicago, University of Illinois Press, 2003, 151 p.
}

\author{
Agnès Devictor
}

1 La première partie de l'ouvrage, rédigée par J. Rosenbaum, figure majeure de la critique américaine, est consacrée à une présentation biographique et critique des films de Kīārostamī. L'A. y inscrit l'œuvre du cinéaste dans un univers cinématographique habité par les grands maîtres, de Tati à Godard. La seconde partie de l'ouvrage, signée par la cinéaste et enseignante Mehrnaz Saeed-Vafa, retrace le contexte politique et sociologique du développement du cinéma de Kīārostamī en Iran, tout en présentant une lecture de chacun de ses films. La troisième partie est un dialogue entre les deux auteurs (daté de septembre 2001) qui justifient leur collaboration par la nécessité de croiser leurs regards. Le chapitre 4 est un long entretien (daté de 1998) entre les AA. et Kīârostamī. L'ouvrage s'achève par une filmographie descriptive du cinéaste.

2 L'un des intérêts majeurs de ce livre - au regard des autres monographies, aujourd'hui abondantes, sur cet auteur - réside dans les indications concernant la réception publique, critique et au sein des professionnels, de l'œuvre de Kīārostamī dans l'Amérique des années 90, et au sein de la communauté iranienne. Rédigés à la première personne, les deux premiers chapitres rendent bien compte du phénomène de découverte, par chacun des AA., de "leur premier Kīārostamī» (découverte pas toujours enthousiaste), et de la construction des regards sur son œuvre. Les AA. racontent aussi les premières rencontres avec ce cinéaste, leurs re-visionnages de films, des anecdotes, mais présentent aussi des éléments sur la situation du cinéma en Iran et aux États-Unis : tout cela rend ce livre particulièrement vivant. Il pourra servir au chercheur qui travaillerait sur la reconnaissance internationale de Kīārostamī, et pourrait aussi contribuer à une « histoire des regards » le jour où elle sera entreprise. 
INDEX

Thèmes : 17.2. Arts du spectacle

\section{AUTEURS}

AGNÈS DEVICTOR

Université d'Avignon 